\title{
MONITORAMENTO E AVALIAÇÃO DOS PLANOS DECENAIS DE EDUCAÇÃO DOS MUNICÍPIOS DA ZONA DA MATA MINEIRA
}

\author{
Rosângela dos Santos' \\ Elisângela Alves da Silva Scaff²
}

\begin{abstract}
RESUMO
O objetivo deste artigo é analisar como se evidencia a participação da sociedade civil no monitoramento e avaliação dos Planos Municipais de Educação dos Municípios da Zona da Mata Mineira. Trata-se de uma pesquisa qualitativa de cunho exploratório e documental, desenvolvida por meio de consulta à página eletrônica do Plano Nacional de Educação do Ministério da Educação (PNE/MEC), a fim de identificar os relatórios de monitoramento e avaliação encaminhados por esses municípios. Em um segundo momento foi realizada leitura dos relatórios com o objetivo de identificar os sujeitos sociais coletivos cuja participação foi predominante nesses municípios. Os resultados apontam uma lacuna entre o percentual de planos elaborados pelos municípios e a quantidade de relatórios de monitoramento apresentados. Também se destaca a escassa participação de instâncias da sociedade civil em parte dos municípios analisados, ressaltando, nesse contexto, o Conselho Municipal de Educação que, entre outros órgãos representativos da sociedade, de modo geral, registrou participação em $60 \%$ dos relatórios elaborados.
\end{abstract}

Palavras-chave: Participação Social. Plano Municipal de Educação. Monitoramento e Avaliaçõa. Planejamento Educacional.

\section{MONITORING AND ASSESSMENT OF DECENNIAL EDUCATION PLANS OF MUNICIPALITIES OF ZONA DA MATA IN MINAS GERAIS}

\begin{abstract}
The in this work was analyzing how the participation of civil Society is evident in monitoring and assessment of Municipal Education Plans of municipalities of Zona da Mata in Minas Gerais. This is a qualitative exploratory research with documental approach developed through Consulting of the National Education Plan of the Ministry of Education (PNE/MEC) website to identify the monitoring and assessment reports addressed by these municipalities. In a second moment, the reports were read to identify the collective social subjects whose participation was prevalent in

\footnotetext{
1 Mestre em Educação pela Universidade Federal do Paraná (UFPR), atua como pedagoga na Universidade Federal de Juiz de Fora (UFJF). Orcid iD: https://orcid.org/0000-0002-58637931. E-mail: rosanngelasants@gmail.com

2 Doutora em Educação pela USP, com pós-doutoramento pela mesma instituição. Professora Associada da Universidade Federal do Paraná, no Programa de Pós-Graduação em Educação. Integra o Núcleo de Políticas Educacionais (NUPE) e é coordenadora da Rede de Estudos e Pesquisas em Planejamento e Gestão Educacional (REPLAG). Orcid iD: https://orcid.org/0000-0002-7682-0879. E-mail: elisscaff@gmail.com
} 
these municipalities. The results point to a gap between the percentage of plans elaborated by municipalities and amount of monitoring reports presented. A scarce participation of civil society bodies in part of municipalities analyzed is also highlighted, rebounding the Municipal Council of Education, which among other representative bodies, altogether, has reported participation in $60 \%$ of elaborated reports.

Keywords: Social participation. Municipal Education Plans. Monitoring and Evaluation. Educational Planning.

\section{MONITOREO Y EVALUACIÓN DE PLANES DECENALES DE EDUCACIÓN DE MUNICIPIOS DE ZONA DA MATA EN MINAS GERAIS}

\section{RESUMEN}

El objetivo de este artículo es analizar cómo se evidencia la participación de la sociedad civil en el monitoreo y evaluación de los Planes Municipales de Educación de los municipios de Zona da Mata de Minas Gerais. Se trata de una investigación cualitativa exploratoria con enfoque documental, desarrollada por medio de consulta em la portada electrónica del Plan Nacional de Educación del Ministerio de Educación (PNE/MEC), para identificar los reportes de monitoreo y evaluación encaminados por eses municipios. En un segundo momento fue realizada la lectura de los reportes con el objetivo de identificar los sujetos sociales colectivos cuya participación fue prevalente en eses municipios. Los resultados apuntan una laguna entre el porcentaje de planes preparados por los municipios y la cantidad de reportes de monitoreo presentados. También se despega la escasa participación de instancias de la sociedad civil en parte de los municipios analizados, señalando, en ese contexto, el Consejo Municipal de Educación que, entre otros órganos representativos de la sociedad, de manera general, hay reporte de participación en $60 \%$ de los reportes elaborados.

Palabras clave: Participación Social. Plan Municipal de Educación. Monitoreo y Evaluación. Planeamiento Educacional.

\section{INTRODUÇÃO}

O monitoramento e a avaliação de planos são importantes atributos do planejamento governamental (CARDOSO JR., 2015). Carregados de significados e apresentando diferentes definições na área, monitoramento e avaliação são aqui compreendidos como um conjunto de procedimentos técnicos, de cunho analítico, sistemático e contínuo que, ao gerarem informações sintéticas e em tempo eficaz, permitem a rápida avaliação situacional e a intervenção oportuna que confirma ou corrige as ações monitoradas (GARCIA, 2001).

Segundo Garcia (2001), o monitoramento se apresenta como procedimento imprescindível para o exercício da avaliação que se pretenda 
um instrumento de gestão. Nesse entendimento, a avaliação tem o objetivo de evidenciar, selecionar e sistematizar informações que subsidiem a adequação de programas e projetos visando o alcance dos objetivos traçados.

Tal compreensão confere à avaliação um cunho diagnóstico, que deve se pautar em informações de fontes oficiais, de modo a dimensionar e caracterizar o fenômeno objeto da intervenção. Sanadas as incongruências e transpostos os desafios, "as demandas de informação e conhecimento voltam-se à avaliação de resultados e impactos do programa ou projeto social" (BORDIGNON, 2014, p. 28) que, por sua vez, implicam uma análise mais minuciosa sobre os mecanismos de intervenção, englobando o cumprimento dos objetivos, as articulações, o desenho, o impacto social, a capacidade de inovação e de rearranjo do projeto.

Nesse contexto, as "avaliações são, como toda atividade na gestão pública, empreendimentos técnico-políticos, de modo que a realização dessas, sobretudo se significativamente abrangentes, não depende apenas do técnico ou gestor do programa" (BORDIGNON, 2014, p. 29).

Atuando como filtro e catalisador, na esfera pública, o monitoramento e a avaliação devem se delinear articuladamente, a partir de informações e conhecimentos de viés técnico, operacional e político, sem que um procedimento se sobreponha ao outro, ou seja suprimido. Nessa perspectiva, "não existe fórmula pronta que possa ser replicada em todos os lugares", especialmente quando se trata do planejamento educacional, mas é necessário que "principalmente os gestores e profissionais da educação articulados aos responsáveis legais por esse processo - coloquem em prática tudo que [...] consta dos planos de educação" (DOURADO, FURTADO, GROSSI JUNIOR, 2016, p. 459).

A esse respeito, vale lembrar que planejar é definir os objetivos, os meios e formas de caminhar, planejamos para abandonar o improviso das ações, para agir objetivamente (BORDIGNON, 2014). Nessa ótica, quatro aspectos são considerados essenciais na execução de um plano, a saber: a não improvisação, o acompanhamento (monitoramento), a avaliação e o 
replanejamento (BORDIGNON, 2014). Enquanto procedimentos engendrados na execução Plano Nacional de Educação - PNE (2014-2024), o monitoramento e a avaliação se desenvolvem como possibilidade a construção de uma outra perspectiva para o planejamento e gestão da política educacional brasileira.

Diante desse cenário, o texto aqui apresentado tem como objetivo identificar como se evidencia a participação social nos processos de monitoramento e avaliação dos planos municipais de educação dos municípios da Zona da Mata mineira. Trata-se de uma pesquisa exploratóriadocumental, desenvolvida por meio de levantamento, no site PNE/MEC ${ }^{3}$, dos planos e relatórios dos 142 municípios que integram a região.

Em um segundo momento foi realizada leitura dos relatórios, a fim de identificar os sujeitos sociais coletivos constantes nas comissões de monitoramento e avalição dos planos desses municípios. Pelo seu caráter exploratório, a pesquisa não pretende analisar as formas que assumiram tais participações, mas identificar, de forma mais geral, como aparecem representadas nos documentos oficiais e quais as entidades com participação mais recorrentes nos diversos municípios contemplados pela pesquisa.

\section{OS SUJEITOS SOCIAIS COLETIVOS E SEU PAPEL NO MONITORAMENTO E AVALIAÇÃO DO PME}

As políticas voltadas para a descentralização, desenvolvidas desde a Constituição de 1988, tornaram possível a redistribuição das competências entre o poder central, os poderes regionais e locais, dando origem a uma nova relação entre Estado e sociedade frente à gestão das políticas públicas. Nessa nova ordem, o "cidadão não é mero sinônimo de eleitor, mas de indivíduo participante, fiscalizador e controlador da atividade estatal" (MACEDO, 2008, p. 187).

A descentralização da ação governamental passa a ser uma forma de compartilhamento do poder, que possibilita ao governo e à sociedade civil

3 http://pne.mec.gov.br/

Revista Exitus, Santarém/PA, Vol. 11, p. 01 - 22, e020173, 2021. 
uma participação de forma mais igualitária na definição das políticas públicas, referendando-se diversos dispositivos para que isso se efetive no âmbito federal e local (ROCHA, 2009).

Nessa lógica, a descentralização não se orientou apenas para que houvesse a participação da sociedade civil na execução das políticas públicas, mas exigiu sua participação nos espaços de deliberação das diretrizes políticas (TEIXEIRA, 2007). Especialmente na área social, o estabelecimento da gestão democrática possibilitou $\mathrm{O}$ surgimento $e$ ampliação de canais de participação, entre os quais se situam os conselhos gestores, instituídos para mediar o diálogo entre os gestores público e a sociedade nos três níveis de governo.

Os conselhos gestores não são uma invenção recente, mas são produtos de um longo processo histórico, cuja origem se perde no tempo e se mistura com a história da política e da democracia participativa (GOHN, 2001). No âmbito educacional, os conselhos surgem como órgãos de assessoramento superior, de caráter eminentemente técnico (BORDIGNON, 2009), constituindo-se em parte da estrutura administrativa estadual e federal, e tinham suas atribuições atrelados aos interesses dos governos (BRASIL, 2004). A partir do final da década de 1970, emergiu uma nova concepção de participação, que se fortaleceu com a reabertura democrática do país. Foi um momento em que

[...] os movimentos associativos populares passaram a reclamar participação na gestão pública. O desejo de participação comunitária se inseriu nos debates da Constituinte, que geraram, posteriormente, a institucionalização dos conselhos gestores de políticas públicas no Brasil. Esses conselhos têm um caráter nitidamente de ação política e aliam o saber letrado com o saber popular, por meio da representação das categorias sociais de base (BRASIL, 2004, p 19).

Inspirada nos anseios dos movimentos sociais, a CF/88 estabeleceu as diretrizes para criação de novos arranjos institucionais, com vistas a propiciar a participação dos cidadãos na gestão das políticas públicas. Fruto das lutas sociais, nascidos sob a égide do espírito da constituição cidadã, os 
conselhos municipais assumiram qualidade de instrumentos de expressão, representação e participação popular.

Instaurou-se assim "um novo padrão de relações entre Estado e sociedade, porque viabilizam a participação de segmentos sociais na formulação de políticas sociais e possibilitam à população o acesso aos espaços em que se tomam as decisões políticas" (GOHN, 201 1, p. 354). Nesse cenário, por meio dos conselhos municipais, a sociedade civil exercita o direito de participar da gestão de diferentes políticas públicas, tendo a possibilidade de exercer maior controle sobre o Estado. Presente nos três níveis de governo, os conselhos têm se consolidado como estratégia privilegiada de democratização das ações, atuando junto a diversos setores da estrutura estatal.

Mediadores do diálogo entre a sociedade e o Governo, por natureza, os conselhos devem lidar com as diferenças, pois "representam o contraditório social" (BRASIL, 2004, p.20), cuidando para não "reduzir a vontade do Governo à da sociedade, ou vice-versa ou, pior ainda, querer reduzir a vontade de ambos a sua própria, situando-se numa "terceira margem do rio' desconectados tanto da sociedade quanto do Governo" (BRASIL, 2004, p. 20, grifo original).

Referenciados no princípio constitucional de gestão democrática do ensino público, os conselhos assumiram nova institucionalidade e mantiveram sua competência normativa, mas passaram a exercer, também, função mobilizadora e de controle social. Segundo Bordignon (2009), a função mobilizadora propicia que o conselho realize reuniões sistemáticas com os segmentos representados, estimule a participação dos setores organizados da sociedade, na discussão das políticas públicas educacionais, e promova evento educacional para discutir e avaliar o Plano Municipal de Educação.

Atuando em defesa do direito de todos a uma educação de qualidade, o CME tem papel fundamental na articulação da participação da sociedade na gestão das políticas educacionais. No âmbito 
educacional, isso pressupõe fazer com que o PME se efetive como principal instrumento norteador das políticas educacionais municipais.

Com vistas à efetivação de sua execução, o PNE (meta 19.3 Lei 13.005/2014) incentiva os entes federados e o Distrito Federal a constituírem mecanismos de acompanhamento da execução dos planos decenais de educação, entre os quais destacam-se os Fóruns Permanentes de Educação, por permitirem a ampliação da participação da comunidade local no monitoramento e avaliação dos planos decenais de educação.

Os fóruns de educação são considerados como espaços públicos de diálogo, debate e encaminhamento de medidas que visam à garantia do direito à educação. Referenciando-se no Fórum Nacional, o Fórum municipal deve ser plural e representativo, sua atuação deve envolver instituições privadas, representação sindicais, estudantes, instituições de pesquisa, famílias e cidadãos dos diversos segmentos da sociedade. Entre outras atribuições, o fórum municipal é responsável por acompanhar matérias legislativas, elaborar o regimento das conferências, acessar estudos e indicadores educacionais, promover debates sobre a educação, e coordenar e articular as conferências de educação.

○ CME e o Fórum são canais para o exercício da cidadania, instrumentos sociais cujas atribuições se interligam e complementam. A atuação articulada dessas instâncias contribui para o fortalecimento da participação social na gestão pública e do monitoramento e avaliação dos PME.

As atividades de monitoramento e avaliação são etapas do processo de planejamento das políticas e programas governamentais. Nas últimas décadas, o monitoramento e a avaliação de organizações, políticas públicas e programas estatais passaram a ter grande relevância para as funções de planejamento e gestão em todos nos três níveis de governo. A efetivação de tais mecanismos parte da necessidade de aumentar a transparência da ação estatal, referente à prestação de contas à sociedade sobre o desempenho dos programas. 
O monitoramento e a avaliação são importantes mecanismos de gestão das políticas públicas. Como parte da atividade governamental, são atividades inerentes ao planejamento, voltadas à sistematização da informação acerca dos aspectos prioritários para sucesso de qualquer programa ou política. O monitoramento requer o exame contínuo dos insumos, atividades, processos e produtos implicados em todas as etapas de uma intervenção, "com a finalidade de otimizar a sua gestão, ou seja, obter mais eficácia, eficiência e, dependendo do alcance do monitoramento, efetividade" (RUA, 2010, p. 5).

Visando à efetivação de um programa ou política, o monitoramento incide sobre as proposições programadas, com intuito de que, se detectada alguma dificuldade, os gestores possam revisar o planejado. Dessa forma, o monitoramento "deve acompanhar a execução de cada programa de acordo com as especificidades, organização e a disponibilidade de informações em cada caso" (CARDOSO JÚNIOR, 2015, p. 9).

A atividade de avaliação não é uma ação isolada, haja vista que consiste em uma das etapas do processo de planejamento das políticas e programas governamentais, e se caracterizada como análise para verificar se o plano originalmente concebido está efetivamente cumprindo com os objetivos e metas traçadas.

Para além das práticas arraigadas de planejamento, o desafio de efetivação do monitoramento e da avaliação do novo PNE apresentam-se como possibilidade para construção de uma outra perspectiva de consolidação do planejamento e gestão da política educacional. Nesse cenário, considerando a organização federativa do Estado brasileiro, a avalição e o monitoramento dos planos municipais se constituem em atividades essenciais para corroborar com o alcance das metas em nível nacional, como defendem Oliveira, Fernandes e Scaff (2021).

[...] as discussões acerca do planejamento educacional em geral e, em âmbito municipal em particular, exigem novas reflexões a fim de situar a materialização da autonomia municipal, sobretudo no que concerne à sua política educacional tendo como epicentro seu 
respectivo plano municipal de educação (OLIVEIRA, FERNANDES, SCAFF, 2021, p. 208).

A fim de identificar como esse processo tem sido desenvolvido em nível local, apresentamos a seguir dados de pesquisa documental, realizada por meio de levantamento de relatórios de monitoramento e avaliação dos 142 municípios da Zona da Mata mineira.

\section{O CENÁRIO DO MONITORAMENTO E DA AVALIAÇÃO DO PME DOS MUNICÍPIOS DA ZONA DA MATA MINEIRA}

Os dados apresentados nesta seção foram levantados junto à página eletrônica do PNE-MEC 4 nos anos de 2019 e 2020. Analisando os 142 municípios pertencentes à Zona da Mata mineira, é possível verificar que estes elaboraram seus planos municipais de educação dentro do prazo estabelecido pelo Plano Nacional de Educação (PNE), ou seja, um ano após a aprovação do referido plano.

Configurados como uma construção coletiva e democrática, alinhados ao PNE e aos instrumentos de gestão municipal, os planos municipais de educação estão sujeitos ao monitoramento e avaliação do cumprimento de suas metas e estratégias que, a despeito da autonomia de cada município, devem contar com a participação de representantes da sociedade civil, se articulando como elemento que aproxima a gestão pública e sociedade civil. (BRASIL, 2016). Para tanto, cada ente subnacional deve instituir uma Equipe Técnica e uma Comissão Coordenadora, que atuarão no monitoramento e na avaliação de seus planos de educação.

Considerando que o período de elaboração do relatório de monitoramento e avaliação do PME pode ocorrer a cada um ou dois anos, e que não foram todos os municípios que conseguiram concluir seus planos no ano de 2015, optou-se por agrupar os relatórios em blocos que englobam dois períodos cada: 2016/2017 e 2018/2019. Como alguns documentos não informaram o ano em análise, empregou-se o ano que constava na página eletrônica no momento do levantamento.

${ }^{4}$ http://pne.mec.gov.br 
Os dados levantados permitem observar que dos 142 municípios que compõem a Zona da Mata, 2 aprovaram seus planos ainda em 2014; 136 aprovaram em 2015; 2 em 2016; e outros 2 em 2017. Esse resultado revela que 97,18\% dos municípios da Zona da Mata aprovaram seus planos de educação dentro do prazo estabelecido pela Lei n. 13.004/2014. Desse total, 50\% elaboraram também o relatório de avaliação da execução do PME.

O número de municípios que apresentaram relatórios de monitoramento diminuiu para 11 no período de 2018/2019 e, desse universo, somente 7 municípios apresentaram relatório de avaliação, o que revela uma redução no número de municípios, quando comparado ao período de 2016/2017. Tal constatação corrobora com a afirmação de Saviani (2014), de que "Uma unidade da federação aprovar em tempo hábil seu plano também não garante que está empenhada em atingir as metas: a aprovação pode ter ocorrido apenas porque essa formalidade facilita a transferência de verbas federais" (SAVIANI, 2014, p. 231).

Apesar de mais de $90 \%$ dos municípios terem aprovado seus planos até 2015, ao pesquisar sobre os relatórios apresentados até o ano de 2019 na plataforma eletrônica PNE-MEC, foram encontrados relatórios de 37 municípios, apenas, dos quais 31 utilizaram algum instrumento legal para instituir a Comissão Coordenadora e Equipe Técnica, como mostra o Quadro 1.

Quadro 1 - Municípios que instituíram Comissão Coordenadora e Equipe Técnica

\begin{tabular}{|l|l|l|l|}
\hline Ordem & \multicolumn{1}{|c|}{ Município } & \multicolumn{1}{|c|}{ Comissão Coordenadora } & \multicolumn{1}{|c|}{ Equipe Técnica } \\
\hline 1 & Acaiaca & Decreto $n^{\circ} 148 / 2017$ & Dec. $n^{\circ} 148 / 2017$ \\
\hline 2 & Abre Campo & Portaria $n^{\circ} 654 / 2018$ & Portaria $n^{\circ} 653 / 2018$ \\
\hline 3 & Alto Caparó & Decreto $n^{\circ} 836 / 2016$ & Decreto $n^{\circ} 846 / 2017$ \\
\hline 4 & Alto Rio Doce & Lei Municipal $n^{\circ} 676 / 2015$ & Sem referência ao ato legal \\
\hline 5 & $\begin{array}{l}\text { Antonio Prado de } \\
\text { Minas }\end{array}$ & Não há qualquer referência & Não há qualquer referência \\
\hline 6 & Araponga & Decreto $n^{\circ} 2.803 / 2017$ & Decreto $n^{\circ} 2.759 / 2016$ \\
\hline 7 & Barra Longa & Decreto $n^{\circ} 871 / 2017$ & Decreto $n^{\circ} 605 / 2014$ \\
\hline 8 & $\begin{array}{l}\text { Barão de Monte } \\
\text { Alto }\end{array}$ & Decreto $n^{\circ} 27 / 2017$ & Decreto $n^{\circ} 25 / 2017$ \\
\hline 9 & Bias Fortes & Portaria $n^{\circ} 048 / 2017$ & Portaria $n^{\circ} 048 / 2017$ \\
\hline 10 & Cajuri & Portaria $n^{\circ} 130 / 2017$ & Portaria $n^{\circ} 130 / 2017$ \\
\hline
\end{tabular}




\begin{tabular}{|c|c|c|c|}
\hline 11 & Caparaó & Port. N N 105/2016 & Resolução de nº01/2017 \\
\hline 12 & Caputira & Portaria n 179/2017 & Portaria n 179/ 2017 \\
\hline 13 & Divino & Decreto n 057/2017 & Decreto $n^{\circ} 057 / 2017$ \\
\hline 14 & Espera Feliz & Sem referência ao ato legal & Decreto $n^{\circ} 1.064 / 2016$ \\
\hline 15 & Eugenópolis & Decreto $n^{\circ} 68 / 2017$ & Decreto $n^{\circ} 68 / 2017$ \\
\hline 16 & Laranjal & Decreto $n^{\circ} 36 / 2017$ & Decreto de n' $36 / 2017$ \\
\hline 17 & Faria Lemos & Não explicita o ato legal & Não explicita o ato legal \\
\hline 18 & Fervedouro & Decreto de n648/2017 & Decreto $n^{\circ} 587 / 2016$ \\
\hline 19 & Muriaé & Decreto de $n^{\circ} 6.487 / 2015$ & Decreto $n^{0} 7617 / 16$ \\
\hline 20 & Oliveira Fortes & Portaria $\mathrm{n}^{\circ} 48 / 2017$ & Portaria $n^{\circ} 48 / 2017$ \\
\hline 21 & Oratórios & Sem referência ao ato legal & Sem referência ao ato legal \\
\hline 22 & Orizânia & Portaria n ${ }^{\circ} 19 / 2017$ & Portaria $n^{\circ} 20 / 2017$ \\
\hline 23 & Palma & Decreto $n^{\circ} 1330 / 2017$ & Portaria $n^{\circ} 5124 / 2017$ \\
\hline 24 & Pedra do Anta & Decreto n 35 /2017 & Decreto $n^{\circ} 35 / 2017$ \\
\hline 25 & Ponte Nova & Não há qualquer referência & $\begin{array}{l}\text { Não há qualquer } \\
\text { referência }\end{array}$ \\
\hline 26 & Porto Firme & Decreto $n^{\circ} 15 / 2015$ & Decreto $n^{\circ} 15 / 2015$ \\
\hline 27 & Pedra Bonita & Decreto $n^{\circ} 29 / 2017$ & Decreto $n^{\circ} 29 / 2017$ \\
\hline 28 & Pedro Teixeira & Lei $n^{\circ} 412 / 2015$ & Lei $n^{\circ} 412 / 2015$ \\
\hline 29 & Raul Soares & Decreto $n^{\circ} 137 / 2015$ & Decreto $n^{\circ} 137 / 2015$ \\
\hline 30 & Rio Espera & Portaria $\mathrm{n}^{\circ} 65 / 2017$ & Sem referência ao ato legal \\
\hline 31 & Rosário de Limeira & Não há qualquer referência & Não há qualquer referência \\
\hline 32 & $\begin{array}{l}\text { Santa Rita de } \\
\text { Jacutinga }\end{array}$ & Portaria $\mathrm{n}^{\circ} 004 / 2017$ & Portaria $n^{\circ} 005 / 2017$ \\
\hline 33 & São Miguel do Anta & Portaria $n^{\circ} 31 / 2017$ & Portaria $n^{\circ} 31 / 2017$ \\
\hline 34 & São Pedro dos Ferros & Ato $n^{\circ} 18 / 2018$ & Ato $n^{\circ} 18 / 2018$ \\
\hline 35 & Teixeiras & Não há qualquer referência & Decreto $n^{\circ} 225 / 2017$ \\
\hline 36 & Sericita & Portaria $\mathrm{n}^{\circ} .1 .952 / 2014$ & Portaria $\mathrm{n}^{\circ} 1.952 / 2014$ \\
\hline 37 & Urucânia & Lei Municipal n 128/2011 & Portaria $n^{\circ} 40 / 2016$ \\
\hline
\end{tabular}

Fonte: Elaboração própria com base em informações do site PNE-MEC (2020).

Por ser prerrogativa da gestão municipal, a criação da comissão coordenadora e da equipe técnica, deve ser realizada por meio de ato legal, ou seja, um instrumento legal capaz de convocar diferentes instâncias municipais, do setor privado e da sociedade civil, a participarem da tarefa de monitorar e avaliar o PME. Nessa direção, o Caderno de Orientação para o monitoramento e avaliação do PME (BRASIL, 2016) sugere que, caso a lei que aprova o plano não tenha previsto a criação de tais instâncias, a gestão municipal pode considerar os integrantes da comissão coordenadora que organizou o processo de elaboração do plano (BRASIL, 2016).

Em desacordo com essa orientação, os relatórios dos municípios de Ponte Nova, Rosário da Limeira e Antônio Prado de Minas não fazem referência à criação das instâncias responsáveis pelo monitoramento e avaliação de seus planos. A mesma situação pode ser observada em 
relação ao relatório do município de Teixeiras, no qual também não consta qualquer referência a respeito da instituição da Comissão Coordenadora. Já o relatório do município de Faria Lemos cita tanto a Comissão como a Equipe Técnica, mas não explicita o ato legal que as instituiu. Os relatórios dos municípios de Espera Feliz e Oratórios não fazem referência ao ato legal de instituição da Comissão Coordenadora, situação que se repete em relação à Equipe Técnica dos municípios de Alto Rio Doce e Rio Espera.

Apesar de constarem na plataforma eletrônica do PNE-MEC, os relatórios de Alto Rio Doce expõem a impossibilidade de elaboração do relatório de Monitoramento e Avaliação do Ciclo I e do Ciclo ll.

[...] em face da análise do Plano, verifica-se que as metas e estratégias do Plano não se encontram alinhadas ao Plano Nacional de Educação - PNE, O que torna necessário fazer as devidas adequações, conforme as 20 metas fixadas no PNE. Em relação às metas propostas no PDME, verifica-se que as metas foram elaboradas por unidade escolar, o que não é o recomendado[...]. Para regularizar a estruturação das metas municipais ao PNE, a Comissão deverá até o fim da primeira quinzena do mês de setembro de 2017, reestruturar as metas e solicitar audiência pública para alterar o PDME por meio de Emenda (ALTO RIO DOCE, 2017).

Da mesma forma, o relatório de Faria Lemos justifica que,

[...] ao assumirem os trabalhos constataram que o monitoramento de avaliação referentes ao ano de 2017 não foram realizados, a Equipe Técnica e comissão Coordenadora anteriores responsáveis pelo monitoramento de avaliação do ano de 2017 encontram dificuldades em se organizarem a tempo de cumprir a tempo o cronograma de relativo ao plano [...] constatamos a impossibilidade de realizar o referido relatório de monitoramento e avaliação do Plano Decenal de educação do Municipal [...] (FARIA LEMOS, 2017).

Em vista do exposto, tais relatórios não foram considerados para fins de cálculo dos percentuais de municípios da Zona da Mata que apresentaram relatório ao MEC. Vale destacar que, apesar de o município de Cajuri ter apresentado relatório de monitoramento e avaliação, ao realizar a leitura, o relatório de monitoramento acessado é referente ao monitoramento do PME do município de Araponga. Com isso, utilizaram-se apenas informações do 
relatório de avaliação do referido município para embasar o presente estudo.

O Gráfico 1 mostra a distribuição dos relatórios de monitoramento e avaliação apresentados no período de 2016/2017 e 2018/2019.

Gráfico 1 - Relatórios apresentados pela Zona da Mata Mineira

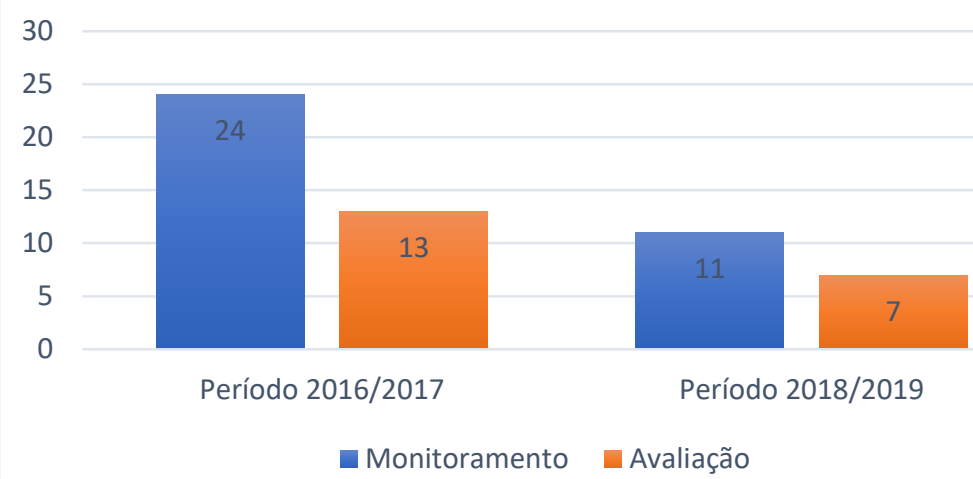

Fonte: Elaboração própria com base em informações do site PNE-MEC (2020).

Percebe-se que, dos 35 relatórios de monitoramento apresentados na plataforma eletrônica PNE- MEC, 24 (68,57\%) são referentes ao período de 2016/2018, e apenas 11 (31,44\%) são do período 2018/2019. Quanto aos relatórios de avaliação, o gráfico mostra que, no período de 2016/2017 foram apresentados 13 (65\%) relatórios, mas esse número diminui para 7 (35\%) no período de 2018/2019.

A discrepância observada, quando comparado o número de municípios que formularam o PME (142) ao número de municípios que apresentaram relatórios (35), sinaliza, em parte, a dificuldade dos municípios em monitorar e avaliar seus planos. Esse resultado corrobora com a afirmação de Dourado, Grossi e Furtado (2016, p. 457), de que "o monitoramento e a avaliação dos planos de educação representam um grande desafio" para a sociedade brasileira.

É importante observar que os municípios que apresentaram relatório do período 2016/2017 o fizeram entre o último e o primeiro ano do mandato municipal, ou seja, em anos de renovação dos mandatos municipais. No entanto, apesar do envio dos relatórios nesse período de transição política 
indicar certa continuidade das ações, os municípios que enviaram relatórios para o MEC no referido período não são os mesmos que apresentaram relatório no biênio de 2018/2019. Mais que revelar a redução do número de relatórios apresentados, tal constatação mostra que, a partir do ano de 2017 , houve descontinuidade das atividades de monitoramento e avaliação nos 24 municípios que apresentaram relatório no biênio 2016/2017.

Considerados mecanismos fundamentais ao monitoramento e avaliação do plano, os relatórios evidenciam que a criação ou não da Equipe Técnica e da Comissão Coordenadora foram articuladas a partir da capacidade política e administrativa de cada ente federado, muitas vezes em dissonância com o próprio PME.

Os documentos dos Municípios de São Pedro dos Ferros, Caputira, Caparaó, Orizânia e Pedro Teixeira não permitiram que se identificasse em qual das instâncias de monitoramento e avaliação ocorreu a participação dos membros relacionados. O relatório do município de São Pedro dos Ferros, por exemplo, destaca que 0 artigo $4^{\circ}$ da Lei n. 118/2015, que aprova $\circ$ plano, estabelece a Secretaria Municipal de Educação (SME), a Comissão permanente de Educação da Câmara Municipal de Vereadores e Conselho Municipal de Educação (CME) como instâncias responsáveis pela execução do PME. Porém, o conselho não consta como membro das instâncias que monitoraram e avaliaram o plano.

O Relatório do município de Caputira apresenta que a Equipe de Coordenação e Equipe Técnica (nomeada pelo Portaria n 179, de 08 de novembro de 2017) foram compostas por representantes da Secretaria Municipal de Educação, do Poder Legislativo e Executivo, de Pais de alunos, de Professores e de Diretores da Rede Municipal, membros do Conselho Municipal de Educação, de Professores e Diretores da Rede Estadual, de Analista Educacional da SRE (Inspetor Escolar), do Conselho da Criança e do Adolescente e Conselho Tutelar. No entanto, o CME não aparece na descrição das instâncias responsáveis pela elaboração do relatório. Por fim, no relatório do município de Rio Espera consta, apenas, que o documento foi encaminhado ao CME para análise. 
Os municípios de Caparaó e Orizânia relacionaram os membros da equipe técnica e da comissão coordenadora em sequência, sem distinguir as instâncias, contudo, como o relatório do município trouxe anexada a Lei 441/2015, que aprova o plano e entre outras providências incumbe 0 Conselho Municipal de Educação e a Secretaria Municipal de Educação e Cultura de monitorar e avaliar do PME, foi possível perceber que o CME participou do monitoramento. Com isso, o referido conselho foi incluído como representante da Comissão Coordenadora.

O relatório do município de Pedro Teixeira cita a participação do CME, mas o referido conselho não consta na composição da Comissão Coordenadora, nem na Equipe Técnica de monitoramento e avaliação do plano do município.

A partir da análise da composição da Comissão Coordenadora dos municípios verificou-se que 18 sujeitos sociais tiveram participação do Conselho Municipal de Educação (CME), 8 com representantes do Conselho Tutelar, $8 \mathrm{com}$ representantes de pais e alunos, 2 com representantes do Fundeb, 4 com representação de sindicato, $2 \mathrm{com}$ representantes do Conselho de Alimentação Escolar (CAE), 3 com representantes da sociedade civil e 3 com participação da Associação de Pais e Amigos dos Excepcionais (Apae). Entre outros coletivos sociais que participaram de uma comissão, estão o Conselho Municipal do Direito da Criança e do Adolescente (CMDCA), ONG Associação São Vicente de Paula, Pastoral da Criança e Associação de Desenvolvimento Comunitário Municipal. 
Gráfico 2 - Sujeitos sociais coletivos representados

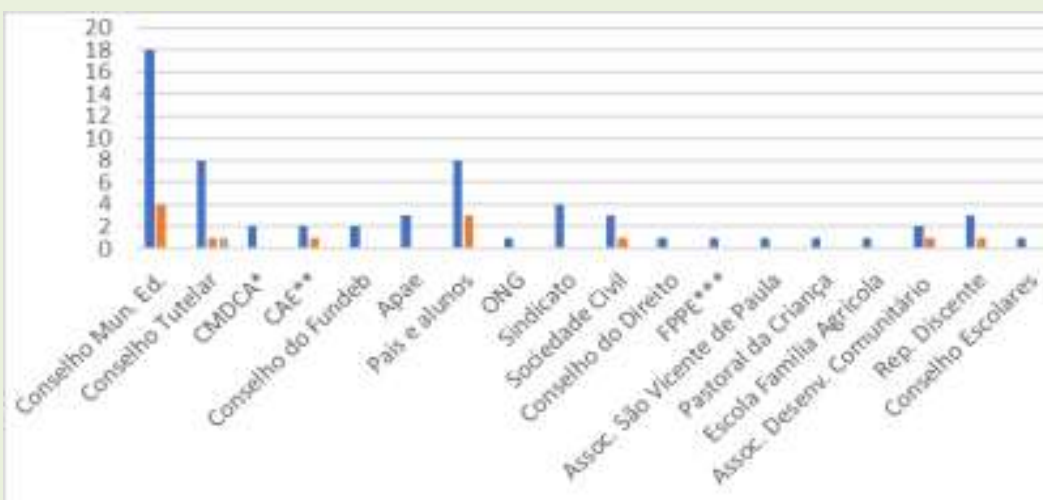

- Comissäo Coordenadora Equipe Técnica Equipe Representativa Scciedade

Fonte: Elaboração própria com base em informações dos relatórios, site PNE-MEC (2019). ${ }^{*}$ Conselho Municipal dos Direitos da Criança e do Adolescente. ${ }^{* *}$ Conselho de Alimentação Escolar. *** Fórum Permanente do Plano de Educação.

Para além dos conselhos gestores de políticas públicas, o monitoramento e avaliação do PME envolveu a participação de pais e alunos, Sindicatos, Pastoral da Criança e associações. É possível perceber, ainda, que o CME se destaca com a maior participação, tanto na Comissão Coordenadora como na Equipe Técnica, seguido pelos Pais e Alunos e Conselho Tutelar. Outro órgão apontado como imprescindível ao monitoramento e avaliação do PME pelo Caderno de Orientação para o Monitoramento e Avaliação do PME, organizado pela Sase/MEC, é o Fórum Municipal de Educação, que aparece como membro da Comissão Coordenadora de um município apenas.

Ainda que o CME tenha sido a instância que mais se repetiu nas comissões (18), a participação desse conselho não se efetivou em conformidade com o caderno orientador, que recomenda, independentemente da situação posta no município, que o Conselho Municipal de Educação (CME) e o Fórum Municipal de Educação (FME) deveriam ser partícipes da comissão.

A ausência de participação do FME, com registro em apenas um município, indica que o monitoramento e avaliação dos planos municipais caminha em dissonância com o item 3 da meta 19 do PNE, que dispõe sobre constituição do Fóruns Permanentes de Educação nos municípios. Observa- 
se, ainda, que a participação dos demais sujeitos sociais coletivos, como o Fundeb (2), Conselho Tutelar (8), CMDCA (1), Cae (2), representação de pais e alunos (8), associação (2), Apae (3), Escola Família Agrícola (1), Pastoral de Criança (1), sindicato (4), e ONG (1) integraram um número menor de comissões, alguns de uma comissão apenas, sendo, portanto, uma participação bastante fragmentada.

É importante lembrar que nem todos os municípios constituíram a Comissão Coordenadora (31) ou explicitaram o instrumento legal que formalizou a sua criação (30). Assim, quando considerados os documentos desses municípios, cujos relatórios fazem referência à participação do $\mathrm{CME}$, mas não permitem identificar se o mencionado Conselho compôs a referida instância, o número de relatórios que contaram com a participação do CME aumenta para 21; do Conselho Tutelar, para 9; e do Fundeb, para 3.

No que se refere à paridade em relação ao número de representante do poder público e da sociedade civil na composição da comissão coordenadora, o Quadro 2 mostra que, em 22 municípios, os representantes do poder público formavam maioria. Além disso, 4 relatórios não continham referência à referida instância, 2 não especificaram a composição e 3 relacionaram os membros nominalmente.

Quadro 2 - Participação poder público, sociedade civil

\begin{tabular}{|l|c|}
\hline Maioria poder público & 22 \\
\hline Maioria sociedade civil & 4 \\
\hline Maioria setor privado & 0 \\
\hline Não específica & 2 \\
\hline Relação nominal & 3 \\
\hline Nada consta & 4 \\
\hline Igualdade de participação & 0 \\
\hline
\end{tabular}

Fonte: Elaboração própria com base nos relatórios (2020).

Observe-se que, dos 35 municípios que apresentaram relatório, 9 $(25,7 \%)$ não continham informações sobre a participação dos sujeitos sociais coletivos. Além disso, percebe-se que a representação do poder público foi 
superior à da sociedade civil em 22 municípios, o que demonstra que a participação vem se constituindo com disparidade entre a o poder público e da sociedade civil, ou seja, sem igualdade de condições (GOHN, 2004).

Em relação à ampla participação da população do município, pode ser observada por meio do Quadro 3, que os relatórios de monitoramento e avaliação foram objeto de discussão em audiência pública em 13 municípios, em pré-conferência em 1 município, em conferência em 3 municípios, e de consulta pública em 1 município.

Como mecanismo aberto de participação, a audiência pública, consulta pública ou conferência permitem que representantes das instituições públicas e de diferentes segmentos da sociedade possam exercer o direito de expressar opiniões e preferências, contribuindo para uma tomada de decisão mais assertiva e com maior aceitação. Tais mecanismos aproximam representantes eleitos e representados, ampliando e fortalecendo o controle social da implementação das políticas públicas.

Quadro 3 - Municípios que realizaram audiência pública, conferência e/ou consulta pública

\begin{tabular}{|c|c|c|c|c|c|}
\hline \multirow{2}{*}{\multicolumn{2}{|c|}{ Município }} & \multirow{2}{*}{$\begin{array}{c}\text { Audiência } \\
\mathrm{N}^{\circ} \text { de } \\
\text { participantes }\end{array}$} & \multirow{2}{*}{$\begin{array}{c}\text { Conferência } \\
\mathrm{N}^{\circ} \text { de } \\
\text { participantes }\end{array}$} & \multirow{2}{*}{$\begin{array}{c}\text { Consulta } \\
\mathrm{N}^{\circ} \text { de } \\
\text { participantes }\end{array}$} & \multirow{2}{*}{$\begin{array}{c}\text { Pré- } \\
\text { conferência } \\
N^{\circ} \text { de } \\
\text { participantes }\end{array}$} \\
\hline & & & & & \\
\hline 1 & Araponga & Não consta & ---- & --- & ---- \\
\hline 2 & Cajuri & Não consta & Não Consta & ---- & ---- \\
\hline 3 & Caparaó & Não consta & --- & ---- & ---- \\
\hline 4 & Eugenopólis & Não consta & ---- & ---- & --- \\
\hline 5 & Fervedouro & 294 pessoas & Não consta & ---- & ---- \\
\hline 6 & Laranjal & Não consta & ---- & ---- & ---- \\
\hline 7 & Muriaé & 64 pessoas & ---- & ---- & ---- \\
\hline 8 & Orizânia & Não consta & Não consta & ---- & Não consta \\
\hline 9 & Palma & Não consta & ---- & ---- & ---- \\
\hline 10 & Pedro Teixeira & ---- & 102 & ---- & ----- \\
\hline 11 & Porto Firme & Não consta & ---- & ---- & ---- \\
\hline 12 & Raul Soares & Não consta & ---- & ---- & ---- \\
\hline 13 & $\begin{array}{c}\text { Santa Rita de } \\
\text { Jacutinga }\end{array}$ & ----- & ----- & Não consta & ---- \\
\hline 14 & $\begin{array}{c}\text { São Pedro dos } \\
\text { Ferros }\end{array}$ & Não consta & ---- & ---- & ---- \\
\hline
\end{tabular}




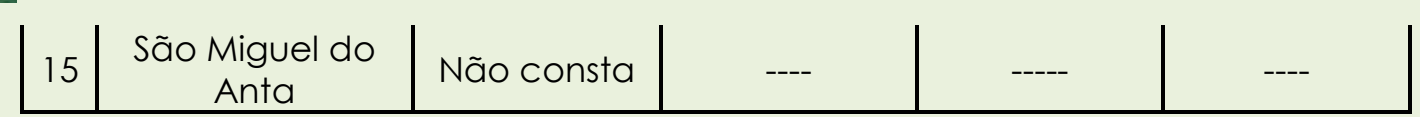

Fonte: Elaboração própria com base em informação do site PNE-MEC, 2020.

O Quadro 3 permite verificar que entre os documentos dos 13 municípios que realizaram audiências públicas, somente 3 apresentam 0 número de participantes envolvidos e entre os 3 municípios que realizaram conferência, apenas 1 explicita o número de participantes. No relatório do município que realizou pré-conferência e do município que realizou a consulta pública não constam o número de participantes. Da mesma forma, nenhum dos documentos analisados discriminam a participação de sujeitos sociais coletivos nesses eventos.

A escassa informação quanto à participação dos sujeitos sociais coletivos nas audiências públicas, conferências e consultas públicas são lacunas que não possibilitaram entender se as articulações ensejadas nesses eventos se caracterizam como participativas. A ausência do FME na comissão coordenadora contribui para a descaracterização do processo participativo, como comprometeu a realização das conferências municipais, sua qualidade e alcance.

Também não podemos deixar de considerar o contexto nacional de enfraquecimento dos espaços participativos e de desconstrução das instituições ligadas diretamente ao monitoramento dos planos, como o FNE, a partir de 2017, culminando com a extinção da SASE, em 2018, e consequentemente da rede de apoio e assessoramento à formulação dos PME, sob sua coordenação.

Em pesquisa desenvolvida no estado de Mato Grosso do Sul, Scaff, Oliveira e Lima (2018) salientam a importância da Rede de Assistência Técnica para Adequação ou Elaboração dos Planos de Educação. Assim, é possível inferir que o arrefecimento do papel coordenador da União pode ter contribuído para a desmobilização em torno do monitoramento e avaliação dos planos em nível local. 


\section{CONSIDERAÇÕES FINAIS}

Considerando o caráter federativo do Estado brasileiro, a materialização das metas e estratégias do Plano Nacional de Educação passa necessariamente pela sua implementação em âmbito local. Por esse motivo, engendra o referido plano a exigência de que estados, municípios e - Distrito Federal elaborem seus planos, em alinhamento com 0 PNE, garantindo seu êxito por meio de monitoramento e da avaliação permanentes.

Os dados apresentados nesse texto permitem identificar enorme discrepância entre a participação do poder púbico e a participação da sociedade civil nas comissões instauradas nos municípios analisados, o que mostra que a efetivação da comissão coordenadora tem se desenvolvido como mero cumprimento de uma exigência legal e, portanto, não se caracterizou como participativa.

Se por um lado a participação de sujeitos sociais coletivos, em maior ou menor número de comissões, pode ser decorrente da autonomia e peculiaridade da conjuntura política de cada município, por outro lado também evidencia que a participação da sociedade civil no monitoramento e avaliação dos PME tem se configurado de forma insuficiente e bastante fragmentada. Essa ausência de sujeitos sociais coletivos no monitoramento e avaliação do PME dos referidos municípios denota um hiato acerca do que ocorrev entre a formulação dos planos e o seu monitoramento. A constatação de que algumas comissões contaram com a participação desses sujeitos não é suficiente para comprovar a qualidade dessa participação.

Ainda assim, foi possível identificar, entre os órgãos representativos que participaram mais ativamente desse processo em diferentes municípios, o Conselho Municipal de Educação (CME). Nesse cenário, importa salientar que, como órgão que contribui na articulação da gestão democrática, a participação do CME no monitoramento e avaliação do PME não exclui a participação de outros sujeitos coletivos sociais, ao contrário, soma-se a elas. 
No entanto, considerando a reduzida quantidade de municípios que apresentaram relatórios, cabe questionar se estes também possuem CME e qual foi a atuação desses conselhos em relação aos processos de monitoramento e avaliação dos planos em cada um deles.

Nesse cenário, compreender o movimento da realidade local frente às mudanças estruturais na configuração do Estado brasileiro e, nessa conjuntura, o afrouxamento dos princípios democrático-participativos conquistados na Constituição Federal de 1988, torna-se elemento imprescindível para a análise desse momento histórico.

\section{REFERÊNCIAS}

BORDIGNON, G. Caminhar da educação brasileira: muitos planos, pouco planejamento. In: SOUZA, Donaldo Bello de, MARTINS, Angela Maria (orgs.). Planos de Educação no Brasil: planejamento, políticas, práticas. São Paulo: Edições Loyola, 2014.

BRASIL. PNE em Movimento. Caderno de Orientações para Monitoramento e Avaliação dos Planos Municipais de Educação. Brasília, DF, 2016. Disponível em:< http://pne.mec.gov.br/images/pdf/publicacoes/pne_pme_caderno_de_orienta coes final.PDF>. Acesso em: 04 mar. 2020.

BRASIL. Câmara dos Deputados. Decreto N 9.759, de 11 de abril de 2019. Brasília, DF, abril, 2019.

BRASIL. Ministério da Educação. Secretaria de Educação Básica. Programa Nacional de Fortalecimento dos Conselhos Escolares. Conselho escolares: uma estratégia de gestão democrática da gestão pública, caderno 6, Brasília, DF, 2004. Disponível em: < http://portal.mec.gov.br/seb/arquivos/pdf/Consescol/ce_gen.pdf>. Acesso em: 15 mar. 2020.

CARDOSO JR., J. C. (org). Planejamento Brasil século XXI: inovação institucional e refundação administrativa - elementos para o pensar e o agir. Brasília: IPEA, 2015.

DOURADO, L. F.; GROSSI JUNIOR, G.; FURTADO R.A. Monitormanento e avaliaçãodos planos de educação: brves contribuições. Revista Brasileita de Polpitica e Administração da Educação. [S.I.], v. 32, n.2, p.449-461, ago. 2016. Disponível em: $<$ https://seer.ufrgs.br/rbpae/article/view/67198 >. Acesso em: 04 mar. 2019.

GARCIA, R. C. Subsídios para organizar avaliações da ação governamental. Planejamento e Políticas Públicas, Brasília, n. 23, p. 7-70, jun. 2001. 
GOHN, M. G. Empoderamento e participação da comunisade m políticas sociais. Revista Saúde e sociedade, v.13, n.2, p.20-31, maio/ago.2004.

MACEDO, P. S. N. de. Democracia participativa na Constituição Brasileira.

Revista de Informação Legislativa. Brasília, DF: Senado Federal - Subsecretaria de Edições Técnicas. Brasília, ano 45, n. 178, abril/junho, 2008. Disponível em: <http://www2.senado.leg.br/bdsf/handle/id/496910 >. Acesso em: 03 mar. 2019.

OLIVEIRA, M. S., FERNANDES, M. D. E., SCAFF, E. A. S. Município, poder local e planos municipais de educação. Cadernos de Pesquisa, São Luís, v. 28, n. 1, jan./mar, 2021. Disponível em:

http://www.periodicoseletronicos.ufma.br/index.php/cadernosdepesquisa/articl e /view/15312/8606. Acesso em: 24 abr. 2021.

ROCHA, M.C.G. da (Org.). Reflexões para ibero-América: avaliação de programas sociais. Brasília: Enap, 2009, p. 25-42. Disponível em:

<http://antigo.enap.gov.br/files/Caderno_ElAPPProgramas_Sociais.pdf>. Acesso em: 19 out. 2019.

RUA, M. das G. Avaliação de Políticas, Programas e Projetos: Notas Introdutórias, 2010. Versão atualizada. Disponível em: https://docplayer.com.br/10008399Avaliacao-de-politicas-programas-e-projetos-notas-introdutorias-versaoatualizada-em-2010.html. Acesso em: 05 mai. 2020.

SAVIANI, D. Entrevista. Revista Retratos da Escola, Brasília, v. 8, n. 15, p. 231-246, jul./dez. 2014. Disponível em: www.esforce.org.br. Acesso em: 24 abr.2021.

SCAFF, E.A.S.; OLIVEIRA, M DOS, S.; LIMA,S. E. de. O planejameto educacional frente às fragilidades da democracia basileira. Educação e Temática Digital ETD. Campinas, SP, v.20, n.4, p. 905-923 out./dez. 2018. Disponível em: $<$ https://periodicos.sbu.unicamp.br/ojs index.php/etd/article/download/8649255/18668/ >. Acesso em:16 mar. 2020.

TEIXEIRA, S. M. Descentralização e partiicpação social: o novo desenho das políticas sociais. Revista Katálysis, Florianópolis, v. 10, n.2, p.154-163, dez., 2007. Disponível em < http://www.scielo.br/scielo.php?script=sci_arttext\&pid=s 1414 49802007000200003\&lng= en\&nrm=iso >. Acesso em: 02 ago. 2019.

Recebido em: 05 de agosto de 2021. Aprovado em: 30 de agosto de 2021 . Publicado em: 24 de setembro de 2021.

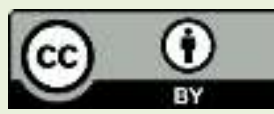

